\title{
SEARCH FOR GLIOMA DIRECT BINDING SITE OF ALKALOID USING PROTEIN-LIGAND ANT SYSTEM $^{\circledR}$
}

\author{
YUSNITA RIFAI* \\ Pharmaceutical Chemistry Laboratory, Hasanuddin University, Faculty of Pharmacy, Makassar, Indonesia. \\ Email: yusnita@fmipa.unhas.ac.id
}

Received: 28 February 2018, Revised and Accepted: 17 September 2018

\section{ABSTRACT}

Objective: This research aims to know the best affinity and the best chemical conformation of anticancer compounds from alkaloid groups that have closed direction to Glioma-associated oncogene using protein-ligand ant system (PLANTS). The interaction energy and hydrogen bond are included as evaluated targets.

Methods: In this research, 27 ligands with root mean square deviation score at $1.614 \AA$ and cyclopamine as native ligand are used. Meanwhile, staurosporinone acts as gliomas directed-binding-site-internal-control. Each ligand is docked in GLI with Protein Data Bank code 2GLI using two methods, GLI contains water and without water.

Results: PLANTS score for native ligand in the first and the second method is -73.9002 and -73.2700 , respectively. Pancracristine, homoharringtonine, and sanguinarine showed PLANTS score closed to the cyclopamine score result, but their hydrogen bond interaction differed from native ligan interaction. Evodiamine ligand has a good score and hydrogen bond to the same amino acid of protein GLI, which are GLU 175 and THR 173 . This result indicated that evodiamine has the same identical mechanism as staurosporinone.

Conclusion: The evodiamine is determined to have the same working mechanism as a GLI inhibitor.

Keywords: Glioma, Alkaloid, Protein-ligand ant system, Oncogene, GLI inhibitor.

(C) 2018 The Authors. Published by Innovare Academic Sciences Pvt Ltd. This is an open access article under the CC BY license (http://creativecommons. org/licenses/by/4. 0/) DOI: http://dx.doi.org/10.22159/ajpcr.2018.v11s3.30034

\section{INTRODUCTION}

Alkaloids are a class of organic compounds most found in nature. Almost all compounds of alkaloids come from plants and are widespread in different types of plants. All alkaloids contain at least one commonly alkaline nitrogen atom and in most of these nitrogen atoms are part of the heterocyclic ring [1].

Docking is currently the most widely used and developed molecular modeling method. Moreover, docking proved to be particularly useful in the selection of compound guides for further development. Docking has three main objectives of predicting the binding of the active side of a ligand, identifying new ligands using virtual screening, and predicting the affinity bond between the compound and the active part of a known ligand. One of the docking apps is protein-ligand ant system (PLANTS) which is a free app that has a quality equivalent to other paid docking apps. In addition, the practical advantages of PLANTS are simple and easy. However, PLANTS does not provide protein preparation, ligand, or visualization functions so that additional applications (6.8) are required.

Studies of anticancer compounds from alkaloid natural substances against the current GLI protein are lacking. In the discovery of new drugs today, the computational method is the development of more efficient modern medicine and the time required more quickly. Increasingly exponential computing capabilities are an opportunity to develop simulations and calculations in drug design. The computer offers a method known as in silico which is a complement of the in vitro and in vivo methods commonly used in the drug discovery process [2-4].

\section{MATERIALS AND METHODS}

Materials

The device used in this study is hardware in the form of a set of computers capable of molecular modeling and computational chemical calculations with specifications: Intel ${ }^{\circledR}$ Core $^{\mathrm{TM}}$ two Duo processor CPU E7500 2.93 GHz, 1.024 GB RAM, and $140 \mathrm{~GB}$ hard drive, as well as Linux operating system.

\section{Protein data collection}

To support the implementation of the research, data on the structure of compounds of the alkaloid species of natural substance have been optimized, as shown in Table 1. In addition, GLI protein structure data from previous research results [5] obtained by Protein Data Bank (PDB) with GDP ID: 2GLI, as shown in Fig. 1.

In this study, the target protein structure data were collected through PDB with GDP ID: 2GLI. These data are the result of X-ray crystallography and crystallization of protein glioma (GLI) which includes structures with active sides and sequences. The molecular model is stored in a. mol2 file.

\section{Molecular docking simulation}

Docking is done by directing the optimized ligand molecule model (compounds of alkaloid) on the active GLI side. Ligands as well as the active side binding are activated by protonation, test ligands are docked on the GLI-binding sides. Then, a calculation of binding of ligands and GLI is applied to various poses that will appear as scores.

Binding visualization between anticancer compounds of natural products and GLI is presented with a software viewer Molegro. Data analysis of the docking values on the sides of the binding pocket was performed. Molecules with the lowest scores indicate the good stability affinity.

In this study, we tested several anticancer compounds of alkaloids natural ingredients to determine their interaction with glioma protein (GLI) which has been studied its activity as an anticancer in vitro and 
in vivo by researchers from various references. Molecular docking simulation is a testing method used in studying the interactions of some of these compounds. A docking procedure is used as a reference

Table 1: List of compounds in the alkaloid group

\begin{tabular}{ll}
\hline Compound & Plants \\
\hline Boldine & Peumus boldus [6] \\
Evodiamine & Evodia rutaecarpa [7] \\
Amphimedine & Amphimedon sp. [8] \\
Vinblastine & Catharanthus roseus [9] \\
Vincristine & Catharanthus roseus [9] \\
Homoharringtonine & Cephalotaxus harringtonia [9] \\
Tylophoridicine A & Tylophora ovata [10] \\
Camptothecin & Camptotheca acuminata [11] \\
Cephalotaxine & Cephalotaxus harringtonia [12] \\
Eupolauramine & Anaxagorea dolichocarpa [13] \\
Sampangine & Anaxagorea dolichocarpa [13] \\
Narciclasine & Narcissus incomparabilis Mill. Var. Helios [13] \\
Pancratistatin & Hymenocallis littoralis [13] \\
Lycoricidine & Hymenocallis littoralis [13] \\
Sanguinarine & Sanguinaria Canadensis [13] \\
Lycorine & Amaryllidaceae [14] \\
Ellipticine & Bleckeria vitensis [15] \\
Epipodophyllotoxin & Podophyllum emodi [16] \\
Rohitukine & Dysoxylum binectariferum [16] \\
Cyclopamine & Veratrum californicum [17] \\
Berbamine & Berberis amurensis [16] \\
Chelidonine & Chelidonium majus [16] \\
Colchicine & Colchicum luteum [16] \\
Matrine & Sophora alopecuroides L. [16] \\
Pellitorine & Piper nigrum [18] \\
Piperine & Piper nigrum [18] \\
Solanine & Solanum tuberosum L. [16] \\
Tetrandrine & Stephania tetrandra [16] \\
Staurosporinone & Synthetic Compound [16] \\
\hline & \\
& \\
\hline
\end{tabular}

to determine the best orientation of one compound to another relative compound. In this study, the targeted compound is glioma protein (GLI).

\section{Data analysis}

Data from the target or GLI compound should be prepared before docking. After GLI data are processed, the data are displayed in YASARA window where two preparation treatments are done in the environment where the water element remains GLI and the water element is removed. The goal is to see the stability of the interaction of the original test compound with the target compound affected by the presence or absence of water elements. The data are then stored in the form (.mol2.).

Next is redocking of native ligands (active compound) on GLI is done. However, the active compound for GLI is not yet known. Therefore, we used cyclopamine-based compound which is the Smo inhibitor (Smoothened) as the native ligand. In the redocking of the active compound on the binding site docking method validation, which obtained the value root mean square deviation (RMSD) of $1.614 \AA$. The RSMD value obtained states that the method has a high or low validity value (RMSD value $<2$ indicates a high validity value) meaning that the ligand copy position is similar to the active compound (Table 2).

The process of the active compounds redocking on GLI can be used to identify the binding site of the protein. This site binding is determined by determining the coordinates where the active compound is located at a radius of $5 \AA$ with the coordinates $\mathrm{x}=-20.5409, \mathrm{y}=5.60607$, and $\mathrm{z}=-0.587999$ and on the bond radius $=40.195$ PHE211, ALA214, SER215, ASP216, ARG217, LYS219, HIS220, THR224, LYS229, LYS240, TYR242, THR243, ASP244, SER246, SER247, ARG249, LYS250.

In the interaction of amino acid residues and ligands, there are also some compounds that do not interact or have no hydrogen bonds such as amphimidine, camptothecin, colchicine, epipodophyllotoxin, eupolauramine, and sanguinarine. It is possible that these compounds have bonds to others but not a hydrogen bonding.

Table 2: Docking results of alkaloid groups against GLI using PLANTS

\begin{tabular}{|c|c|c|c|c|}
\hline \multirow[t]{2}{*}{ Sample } & \multirow[t]{2}{*}{ Conformation number } & \multirow[t]{2}{*}{ The best conformation } & \multicolumn{2}{|c|}{ Scoring of PLANTS ${ }_{\text {CHEMPLP }}{ }^{\circledR}$} \\
\hline & & & Without water & With water \\
\hline Cyclopamine & 10 & 10 & -73.2700 & -73.9002 \\
\hline Staurosporine & 4 & 4 & -70.8266 & -70.8912 \\
\hline Amphimidine & 10 & 10 & -67.1141 & -69.4706 \\
\hline Berbamine & 10 & 10 & -56.5199 & -54.4644 \\
\hline Boldine & 10 & 10 & -51.9760 & -51.9570 \\
\hline Camptothecin & 10 & 10 & -72.3414 & -73.5372 \\
\hline Cephalotaxine & 10 & 10 & -64.6274 & -64.2058 \\
\hline Chelidonine & 10 & 10 & -66.4341 & -77.0578 \\
\hline Colchicine & 10 & 10 & -33.5994 & -31.0033 \\
\hline Ellipticine & 10 & 10 & -65.1740 & -63.4189 \\
\hline Epipodophyllotoxin & 10 & 10 & -46.775 & -46.8651 \\
\hline Euplauramine & 10 & 10 & -50.1766 & -49.4534 \\
\hline Evodiamine & 10 & 10 & -71.3117 & -71.5565 \\
\hline Lycoridine & 10 & 10 & -66.8048 & -72.7524 \\
\hline Lycorine & 10 & 10 & -68.6914 & -64.1283 \\
\hline Matrine & 10 & 10 & -62.6821 & -62.1120 \\
\hline Pancracristine & 10 & 10 & -74.0450 & -73.9727 \\
\hline Pellitorine & 10 & 10 & -63.9105 & -63.6538 \\
\hline Narciclasine & 10 & 10 & -72.2331 & -66.3553 \\
\hline Piperine & 10 & 10 & -75.2844 & -65.2317 \\
\hline Rohitukine & 10 & 10 & -64.1821 & -62.4513 \\
\hline Sampangine & 5 & 5 & -66.3461 & -64.9847 \\
\hline Sanguinarine & 10 & 10 & -71.7399 & -75.7460 \\
\hline Tetrandrine & 10 & 10 & -50.0278 & -44.4786 \\
\hline Tylophoridicine A & 10 & 10 & -69.3233 & -74.2702 \\
\hline Solanine & 10 & 10 & -80.7808 & -76.8014 \\
\hline Vinblastine & 10 & 10 & -71.3585 & -71.2605 \\
\hline Vincristine & 10 & 10 & -73.1619 & -68.0347 \\
\hline
\end{tabular}




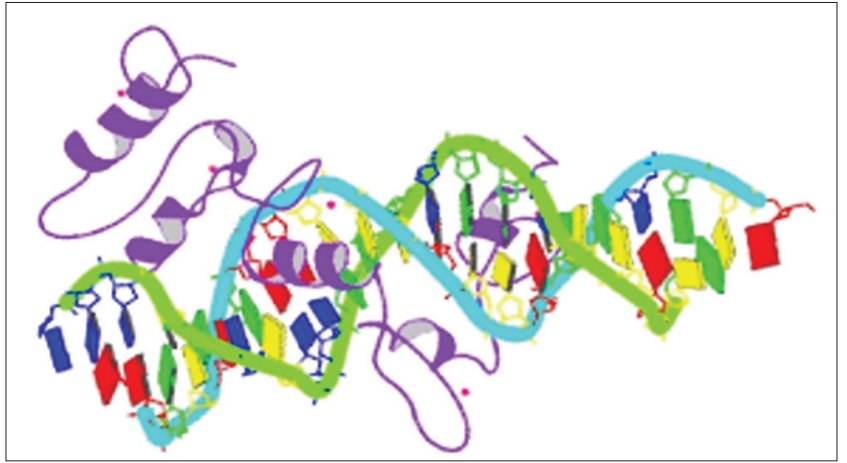

Fig. 1: Structure of GLI from RCSB protein data bank

\section{CONCLUSION}

Camptothecin, evodiamine, homoharringtonine, pancracristine, sanguinarine, and vinblastine have a PLANTS score close to cyclopamine in both aqueous and non-aqueous environments. Therefore, these compounds are predicted in silico having an affinity identical to the affinity of cyclopamine to the glioma protein. The evodiamine compound has an interaction of the same glioma protein with staurosporinone of GLU 175 and THR 173 so it is predicted to have the same working mechanism as a GLI inhibitor.

\section{CONFLICTS OF INTEREST}

The author declares that they have no conflicts of interest.

\section{REFERENCES}

1. David JN, Gordon MC. Natural products as sources of new drugs over the last 25 years. J Nat Prod 2007;70:461-77.

2. Rifai Y, Tani HB, Nur M, Aswad M, Lallo S, Wahyudin E. Synthesis, molecular mechanism and pharmacokinetic studies of new epoxy lignan-based derivatives. Arch Pharm 2016;349:848-52

3. Evangelista M, Tian H, Sauvage FJ. The hedgehog signaling pathway in cancer. Clin Cancer Res 2006;12:5924-5.

4. Kroemer RT. Molecular modelling probes: Docking and scoring. Biochem Soc Trans 2003;31:980-4.

5. Leach AR, Shoichet BK, Peishoff CE. Docking and scoring, perspective: Prediction of protein-ligan interactions. Docking and scoring: Success and gaps. J Med Chem 2006;49:5851-5.

6. Marie CL, Michael J, Rachid S, Jackies F, Michele S, Francois M, et al. Hepatoprotective and antiinflammatory effects of a traditional medicinal plant of chile, Peumeus Boldus. Planta Med 1991;49:110-5.

7. Jiang J, Hu C. Evodiamine: A novel anti-cancer alkaloid from Evodia rutaecarpa. Molecules 2009;14:1852-6.

8. Kumar D, Rawat DS. Marine natural alkaloids as anticancer agents. Res Signpost 2011;37:213-68.

9. Shoeb M. Anticancer agents form medicinal plants. Bangladesh J Phamacol 2006;2:35-40.

10. Ying-Yue Z, Xue-Shi H, De-Quan Y, Shi-Shan Y. Antitumor alkaloids isolated from Tylophora ovate. Acta Botanica Sinica 2002;44:349-53.

11. Padmanabha BV, Chandrashekar M, Ramesha BT, Gowda HC, Gunaga RP, Suhas S, et al. Patterns of accumulation of camptothecin, an anti-cancer alkaloid in Nothapodytes nimmoniana graham, in the Western Ghats, India: Implications for identifying high-yielding sources of the alkaloid. Curr Sci 2006;90:95-100.

12. Powel RG, Rogovin SP Jr., Smith CR. Isolation of antitumor alkalois from Cephalotaxus harringtonia. Ind Eng Chem Prod Res Develop 1974;13:129-32.

13. Lucio AS, Almeida JR, Barbosa-Filho JM, Pita JC, Branco MV, Diniz MF, et al. Azaphenanthrene alkaloids with antitumoral activity from Anaxagorea dolichocarpa sprague and sandwith (Annonaceae). Molecules 2011;16:7125-31.

14. Ingrassia L, Lefranc F, Mathieu V, Darro F, Kiss R. Amarylldaceae isocarbostyril alkaloids and their derivates as promosing antitumor agents. Trans Oncl 2008;1:1-13.

15. Liu XS, Jiang J, Jiao XY, Wu YE, Lin JH, Cai YM. Lycorine induces apoptosis and down-regulation of mcl-1 in human. Cancer Lett 2009;274:16-23

16. Kaur R, Singh J, Singh G, Kaur H. Anticancer plants a review. J Nat Prod Plant Resour 2011;1:131-6.

17. Mahindroo N, Punchihewa C, Fujii N. Hedgehog-gli signaling pathway inhibitors as anticancer agents. J Med Chem 2009;52:3829-45.

18. Murlidhar M, Goswami TK. Piper nigrum and piperine: An update. Phytother Res 2013;27:1121-30. 